\title{
MIXING METHODOLOGIES IN ESL: CUMULATIVE OR CONTRADICTORY?
}

Doug Absalom

It is often assumed that an eclectic approach to teaching a second language is desirable, as no single method can be regarded as universally ideal. Such a mixed methodologies approach was adopted in an ESL course at the University of Newcastle in Australia, deliberately incorporating the use of CALL techniques to enhance the success of a variety of other methods. Surprisingly, students who reported to have enjoyed the CALL classes and testified to their practical usefulness fared worse in the examinations than students in the previous five years, when CALL techniques were not used. The writer speculates on the possible reasons for this unexpected finding, and cites a further example of the lack of success of a mixed methodologies approach.

Dit word dikwels aangeneem dat 'n eklektiese benadering tot tweedetaalonderrig wenslik is, aangesien dit aanvaar word dat geen onderrigmetode as universeel ideaal beskou kan word nie. Met dié aanname in gedagte, is 'n gemengde metodologiese benadering gebruik vir die aanbieding van 'n Engels tweedetaalkursus aan die Universiteit van Newcastle in Australië. Die kursus het, bo en behalwe die gewone tweedetaalonderrigmetodes, ook gebruik gemaak van CALL-tegnieke (d.w.s. rekenaar-ondersteunde leertegnieke) met die bedoeling om die taalverwerwingsproses op dié wyse te bevorder. Teen die verwagting in het studente wat aangedui het dat die rekenaarklasse genotvol en waardevol was, swakker in die eindeksamen gevaar as die gemiddelde student wat geen CALL-onderrig in dieselfde kursus oor die vorige vyf jaar ontvang het nie. Die skrywer spekuleer oor die moontlike redes vir hierdie onverwagte swak vertoning en verwys na nog 'n voorbeeld van onsuksesvolle resultate na die gebruik van 'n gemengde-metode-benadering.

Most language teachers recognise that the "perfect" method of teaching a second language is yet to be discovered. Thus many tend to be fairly flexible and eclectic in attempting to adapt methodologies to the requirements of students, persevering with formats that seem to produce good results and discarding those that don't. It has even been claimed that: "No method has been shown to be significantly better than any other method. In fact, a glance at textbooks and syllabuses being produced now would tend to support this view of our uncertainty - the new emphasis is on eclecticism" (Mann, 1992:51).

Consequently, a typical ESL classroom in Australia may begin with some baroque music, as recommended for Suggestopedia, go on to some TPR exercises, followed by an audio-lingual 
session in the language laboratory, a written translation procedure, a role play and then an excursion to an Immersion Village specially constructed for the topic involved in the functionalnotional process of the class programme. Through this 'shotgun' approach, teachers tend to believe that at least one method will match a student's learning style. The more "successful" procedures will be repeated while the less successful will be discarded, "success" usually being measured in terms of student response. The obvious ad hoc nature of such a procedure is often ignored under the guise of the process being tuned to the greater good of the students. Part of the aim of this paper is to investigate whether such a justification is tenable.

The advent of Computer Assisted Language Learning (CALL) techniques has given rise to many questions relating to ways in which the computer can supplement, or perhaps even replace, procedures that have already been established in our methodologies. It has usually been expected that the type of intrinsic motivation generated by the current interest in computer technology could only be beneficial to any teaching procedure. However, the following report of a research project conducted in Newcastle during the 1993-4 summer period (c.f. Xiao Xi and Doug Absalom, 1995) with a group of students learning English as a second language serves to cast some doubt on the implicit faith that tends to be placed in this widely accepted practice.

The University of Newcastle English Language Centre (UNELC) has, since its inception some six years ago, adopted an immersion programme to teach English as a second language to overseas students wishing to enter courses at the University. For five hours per day, five days per week, students attend classes in the target language and participate in language activities designed to help them acquire the types of English that they will need to be able to undertake their projected University courses successfully. Theme areas that are treated include those relating to Technology, Ecology, Health and Australiana, as well as a number of consciousness raising procedures about the target language and the ways in which people learn languages. These activities are supplemented, in an "eclectic" way, by excursions, development of research techniques, essay and report writing skills, seminar presentation procedures and computer awareness and usage programmes. The last named procedure has, until recently, been limited to voluntary (but very well attended) classes of two to three hours' duration which students attend about once per month.

During the ten week period over the summer of 1993-4, it was decided that a more extensive use should be made of the potential offered by the versatility of CALL techniques in an attempt to increase and diversify students' participation in target language procedures. Accordingly, extra voluntary classes were scheduled on a daily basis, with each student having the opportunity of attending one two-hour class per week. Of the 108 students enrolled at the Centre at that time, 94 accepted the invitation to attend, and although attendance varied over the next eight weeks, from $98 \%$ to a low of $64 \%$, students on average received an extra 10 hours of target language participation in a medium with which they had previously had little experience. The process also opened up the possibility of further self-directed learning in the same medium, and just under $50 \%$ of the participants reported that they took advantage of this opportunity. This may well have added a further estimated 10 hours of direct exposure to those students' activities. 
The lesson procedures took the form of introducing students to the e-mail facility of the University's computer network, and allowing, initially, interchange to take place in the classroom before students went on to the full use of the process by communicating in English with users in other parts of the world. The students were also introduced to a number of extra software programmes, notably Globe, that would allow them to extend their research techniques, as well as to several games that they could play, either alone or in network, with the object of increasing enjoyment and participation, particularly for those students who had been characteristically hesitant to take part in the real or simulated communication procedures in the immersion programme. Other games and participatory procedures included Hugo, Civilizations, touch typing, word-processing and a voice card that offered students a pictorial representation of their utterances.

Our general observations had led us to expect that many of our students would, on entrance to our course, display better reading and writing skills than speaking and listening skills, this probably being due largely to writing-centred methods and materials that they had been exposed to in their previous language learning procedures. Thus it was believed that the "e-pal" process, which made use of these writing skills to facilitate a communicative interchange in something approaching a "real life" situation, would provide an admirable "half-way" stage in students' transitions into facility in spontaneous oral interaction. Confidence gained from success in computerised communication, which is comparatively free of the type of interpersonal tension often present in a normal conversation, would presumably have a beneficial effect on students in their transfer to the real life situation.

The e-mail process, for the purposes for which we wished to apply it, was seen to have the following advantages:

(i) Ease of access; computer terminals in the networked laboratory were readily available during the summer vacation when most of the usual student population was absent from the campus.

(ii) Ease of operation; once a student had been registered and could log in to the network, he/she had only to type in the category "mail" and use such comands as "send", "read" and "reply".

(iii) Efficiency; after the message is typed, the student has only to press the $\mathrm{Z}$ key to direct the message to its destination.

(iv) Economy; electronic mail is cheaper and more time effective than conventional mail, especially for overseas communication.

(v) Echo-stimulation; once a student receives a message, it is almost instinctive to want to reply immediately, either out of politeness or else through having something to communicate about the topic being discussed. The automatic nature of the "reply" command helps to facilitate this process, and the novel experience of communicating so 
directly with someone in another country adds motivation to the student's need to respond.

The project was embarked upon with enthusiasm. Not only did it appear to conform completely to the Centre's language immersion policy, with instruction in a specific content area (i.e. computer operation, rules and uses of games and facility in operating e-mail) being totally in the target language, but also it appeared to achieve Lian's (1987) aim of the three A's - awareness, autonomy and achievement in language learning. By producing a printout of their interaction, students were able to reflect on their "conversations" and become consciously aware of the ways in which meaning transfer had occurred. With students operating their own individual terminals, the power of their autonomy and their ability to contribute at any time of their choice was a strong motivating factor. Finally, the fact that they had actually communicated with real people in other parts of the world, imparting and receiving. "real world" information and advice, was seen as providing an appropriate sense of achievement.

The sessions were lively, with students being adventurous in their production of the target language. It seems probable that this sense of adventure was enhanced by the anonymity of the computer screen protecting students from the social embarrassment that their variant productions might bring in a face-to-face situation. In fact, many students extended this anonymity, adopting false names and creating persona which they role-played in internet until some other class member guessed their real identity.

Not all of the process was seen as being just fun though; the Globe software in particular was used extensively to provide facts and figures for student essays and seminars. Thus classes often had a direct sense of academic purpose, particularly at the time that essays were due to be submitted. This was also seen to be important in terms of the process of students' being able to transfer the language skills acquired in the computer lab to the other areas of their course, especially the examination.

Given all of these apparent advantages, both staff and students looked forward with optimism to the examination results at the end of the ten-week period. Since students had received an average of an extra ten hours' instruction through the medium of the target language, in a subject area that they enjoyed and which was seen as being both motivating and useful, and also directly related to the Technology theme discussed in the course proper, tutors felt sure that there would be a substantial improvement in examination marks, compared to previous groups that had not enjoyed these advantages.

However, the final results were extremely disappointing with only 69 of the cohort of 94 students reaching the required University entrance level of an equivalent 6.5 IELTS band. This represented a pass rate of $73.4 \%$ compared to the established rate of just over $80 \%$ for the previous five years. The variation of $7 \%$ was almost double the established deviation over the five year period, yet the tests themselves had remained substantially the same. In the interview section of the exam, only a handful of the students (six were readily identifiable) showed any marked improvement in their speaking abilities. Furthermore, the 14 students who had not participated in the computer classes did slightly better in the overall testing, 11 of these passing, which represents 
a pass rate of $78.5 \%$. However, since several of these were quite accomplished students who already had advanced computer skills, and possibly language and study skills as well, the group may well have been atypical.

What explanation could possibly be offered for this disappointingly negative result? It appeared that the group at the outset showed no notable deficiencies in relation to other beginning groups over the previous five years, and the examiners were adamant that the examination standard had not been lifted, since the aim of the Centre was to maintain parity with standards established by the International English Language Testing System. A hurriedly compiled questionnaire was distributed to students and discussions were conducted with the teachers who had processed the examinations, in an attempt to find some reasonable explanation for the disappointing results.

One possiblity that presented itself was that the type of language that had been produced during the internet activities was less formal than that normally used under written exam conditions, and a transfer of such habits to the written component of the examination may have significantly influenced examiners' assessments of students' language. Examples of the type of combination of spoken and written forms found in the internet printouts included items like "I much like you a lot" and "That place have a yuk' feeling for me". However, the examiners claimed not to have noted any strong tendency in that direction (at least, no more than usual) during their marking of the written sections of the exam. A further possible explanation related to the intrusion of "extraneous variables" into this particular course, and it was indeed the case that there had been a major change in senior management of the Centre four weeks into the ten week course. However, this had been accomplished with a minimum of disruption to student programmes and the outgoing director remained accessible to students for the duration of the course. Thus, any effect of the change on student attitudes and results was thought to be minimal. Another possibility related to the amount of student time that the computer classes had taken up. Is it possible that students would have spent that time more profitably in studying, or in real life conversations instead of simulated ones? Experiences of the teachers at the Centre would suggest that this was not a strong possibility, since private study has not been regarded as a time-efficient way of acquiring second languages, and real life conversations among students outside class time were more often in their native language than in the target language. Nevertheless, this variant use of time had to be kept in mind as a possible contributor to the disappointing results.

The questionnaires were not as revealing as might have been hoped, either. Only a $30 \%$ response was received, partially due to the hurried nature of the distribution, and partially to the fact that it was a busy time of the year with students needing to enrol in their new courses, attend orientation lectures and acquire textbooks and course outlines. It is probable that student disappointment may also have played a part in the poor return. Later random questioning of some students also revealed a very strong "compartmentalising" attitude, expressed as "We have finished our Elicos course now. We will never forget you", and the questionnaire did appear to be something of an afterthought when students were entering a new phase of their learning. This particular viewpoint may well provide a clue regarding some basic misunderstandings in our teaching procedures.

The questionnaires did, however, provide some worthwhile feedback. All but one of the respondents claimed to have enjoyed the computer classes very much, and all, including the one 
who did not enjoy the procedure, insisted that the computer class should be made a part of the permanent instruction section of the course. In reply to the question relating to the usefulness of the classes, the majority of the respondents said that "They were O.K.", and in reply to the question relating to the area of their language which they thought the computer classes had helped most, none of the respondents nominated speaking. Most selected General Knowledge as the area most improved, while some nominated Grammar and Sentence Organisation. Several respondents felt that the Internet procedures, while being enjoyable, were not directly related to their University work and so were a waste of time.

It thus appeared that the overall response revealed a high level of enjoyment, but only mediocre support for "usefulness"; paradoxically, there was a strong push to have the processes included in the compulsory sections of the course. This suggests that the notion of "compartmentalising" mentioned above may be worthy of further consideration, since for many students of Asian background, the process of enjoying an activity appears largely to preclude that activity and its associated features from the realms of usefulness. There was already a strong suspicion among teachers at the Language Centre that skills taught there were not being adequately transferred by students to the "larger" more formalised world of their University courses. In microcosm, it also seemed necessary for teachers to consider ways of making the activities in the computer laboratory more applicable to the abilities required in the examination room. As mentioned earlier, it was thought that the use of the Globe software to assist in research for essays would go some way towards facilitating this transfer, but apparently this was seen as being no more than a happy coincidence. Even the teaching of word-processing skills for the purpose of writing essays seems to have been regarded as an isolated activity that was not directly testable, and thus not fully related to the serious business of passing the language exams. Consequently, transfer of skills was apparently inhibited.

Clearly, the hastily constructed investigation did not supply enough empirical evidence to claim that, firstly, the extra procedures in the computer laboratory did significantly improve students' communicative competence, and secondly, that any possible improvement failed to be transferred because of the strong "compartmentalising" procedures that students went through in labelling the CALL section as non-compulsory, and thus of limited usefulness in their "real" task of learning language. However, the strong push by the questionnaire respondents to have CALL included in the compulsory section of the course certainly suggests that such may be the case. Perhaps a clearer indication of the effects of this computerised learning may have been gleaned had students been examined using word-processing programs to construct their answers, though such a process brings into play the usual questions of the borderline between language skills that have been acquired by the student and computer skills that involve the use of spelling check, thesaurus and other "artificial" aids.

The major effects of aspects of the affective domain on the quality of language learning have been observed and reported on in a number of places in the literature (Bley-Vroman, 1989, Absalom 1994), and even though the immersion procedures at the English Language Centre concentrate on enjoyment as a principal contributor to effective language acquisition, it is apparent that the compulsory nature of those processes tends to categorise them in students' minds as being related to exam performance. Although the computer classes were time-tabled in the same way as 
regular classes, the fact that they were taught by "researchers" rather than regular teachers seemed to lend a different "character" to the nature of enjoyment. The differences in student responsibilities required by the computer laboratory as opposed to the regular classroom appeared to constitute a significant role variation, so that students felt free to come and go from the laboratory, to take photographs at various times during the lessons and were less constrained by time limitations on activities. Such a mismatch in requirements, which can readily be seen as a methodological variation, seems to have been integral to the failure of the skills acquired during the computer classes being transferred in a cumulative way to those used in the examinations.

A second example of an eclectic methodology observed during this time concerred a Korean nursing student who had already achieved Masters degree status in her home country and wished to enrol as a Doctoral student in Australia. In accordance with University policy, she had to pass the English exams at the Language Centre with an equivalent of an IELTS band of 6.5. As well as participating in the Immersion procedures conducted at the Centre, the student (let's call her "Kim") was requested by her future supervisor to translate her Masters Degree thesis from Korean to English. Since the subject matter was obviously of considerable interest to the student, it was thought that at least some of the principles of immersion were being conformed to. As it seems clear that some informal translation procedures almost inevitably play a part in second language acquisition anyway, it was assumed that a limited formal procedure in this area, stretched out over a period of twenty weeks, would not interfere greatly with Kim's acquiring English in the immersion programme.

However, the combination proved to be a failure. Kim's language abilities in her post- graduate work were seen to be inadequate, despite her having reached the required level in her English entrance exams. She was first required to complete some extra Masters degree course work before starting her research, and the disapponting results of this course work caused her to withdraw her candidature and return to her own country. A preliminary assessment of this particular student suggests that, as a mature (she was 37) committed person with a good track record in both her specialisation and in language learning, including some University study of French and German, she was expected to make a far more successful attempt at her course than was the case. Could it be possible that the mixing of methodologies had been instrumental in hampering her progress at University?

An investigation of the procedures that Kim went through in translating her Masters degree thesis highlights some particular problems. Firstly, there was considerable difficulty in establishing an appropriate register. In her foreword, Kim's translation read: "I thank from the bottom of my heart Professor X: even if she was busy, she gave me consideration and love", and a little later in the thesis she wrote: "some clinics have close out; they have just shut up shop". There was also a reference to a psychiatrist as a "shrink", and a number of other non-formal terms were evident in the translation. Kim herself pointed out the difficulty of translating "special" vocabulary, and also said that sentences in Korean were often too long to be put comfortably into English. She made valiant attempts to formalise her vocabulary choice, but these too sometimes suffered miscue as in: "As Korean society has experienced a rapid speed of industrialisation and urbanisation, more population have left local towns to live in bigger cities and receive modernised medical services". She had crossed out "people" and substituted "population" since it seemed more formal to her. 
It became clear, with the length of sentence problem, that Kim constantly had to make a choice between including all of the information contained in her thesis, or else just giving a general "meaning" translation. That she chose the latter path was made obvious when it eventuated that her thesis of 104 pages of Korean was reduced to just over 40 pages of double spaced handwriting in English. An example of this was her reduction of a full page of Korean to a single sentence in an isolated paragraph: "Normal delivery might be regarded not as an illness, thus providing opportunity to disregard it in the current medical insurance benefit". A later commentary by Kim revealed that the original page had dealt with social, political and economic aspects that she found to be either too difficult to communicate in her second language, or else not sufficiently interesting to be communicative in the ways that her Immersion course was encouraging.

It seems highly probable that, in this instance, the established procedure of an eclectic approach to methodology may have been detrimental to the student's progress. While Immersion concentrated on enjoyment and communicative competence, the translation procedure required accuracy and detail. The methods adopted within the Language Centre incorporated emotive responses in a spontaneous way, whereas the environment of a thesis translation emphasized dispassionate formality. It may be that the sheer volume of work encompassed by the two methods became too much for the student. It may also be argued that the translation procedure alone may have been more appropriate for Kim's lifestyle and directions, though it is generally held that control of communicative genres is a prerequisite for facility in specialised ones. It seems apparent within this case study that, if some use had been made of one-to-one tutoring in the translation method by a teacher who was also involved in the daily Immersion procedures, some of the "compartmentalisation" aspects may have been overcome, but it is also clear, from the illustrations of genre variation shown above, that our own daily language processes require categorisations of particular types and that a mixing of methodologies may serve to blur such distinctions.

What these two instances of method mixing in language learning appear to demonstrate is, firstly, a degree of support for the contention that: "If one moves on from one method, any method, to another, any other, it was probably partly because the method before it was seen to be inadequate. But unfortunately, learning a language is difficult, and all methods in themselves are inadequate" (Mann 1992:51). Secondly, however, it seems that even a combination of two or more methodologies, under the currently popular "eclectic" approach, is likely to provide shortcomings as well. While current viewpoints may well hold that a combination of methods will allow one of the contributing formats to make up for shortcomings in the other, teachers must be aware of possible functional contradictions within these combinations. Unfortunately, as shown in the two instances summarised in this paper, the failure to realise such shortcomings led to very severe setbacks in the careers of a number of students. 


\section{REFERENCES}

ABSALOM, DJ. 1994. Saturation, immersion or extraneous variables. In Lee Ik-Hwan (Ed.), Linguistics in the morning calm 3, Seoul: Hanshin Publishing Co.

ADAMSON, HD. 1993. Academic competence. Theory and classroom practice: Preparing ESL students for content courses. New York: Longman.

BLEY-VROMAN, R. 1989 "The logical problem of foreign language learning." In Gass, S and J.Schachter (Eds), Linguistic Perspectives on Second Language Acquisition. Cambridge: Cambridge University Press:41-68.

COOK, V. 1991 Second Language Learning and Language Teaching. London: Edward Arnold.

LIAN, AP. 1987. Awareness, autonomy and achievement. In Revue de Phonetique Applique, 82-84:167-184.

MANN, C. 1992. Universities and LOTE Proficiency. In Australian Review of Applied Linguistics, series S, (9):49-68.

RICHARDS, JC AND TS ROGERS. 1986. Approaches and Methods in Language Teaching. Cambridge: Cambridge University Press.

XIAO XI AND DOUG ABSALOM. 1995. Mixing Methods: Immersion and CALL. In Australian Association of Language Immersion Teachers. Vol. 2(1). 